\title{
FABRICATION AND CHARACTERIZATION OF 3D PRINTED, 3D MICROELECTRODE ARRAYS FOR INTERFACING WITH A PERIPHERAL NERVE-ON-A-CHIP ${ }^{\circledR}$
}

\author{
Avra Kundu ${ }^{1}$, Laurie McCoy ${ }^{2}$, Nilab Azim ${ }^{1,3}$, Hieu Nguyen ${ }^{2}$, Charles Didier ${ }^{1,4}$, Tariq \\ Ausaf $^{1,5}$, Anup D. Sharma ${ }^{2}$, J. Lowry Curley ${ }^{2}$, Michael J. Moore ${ }^{2,6}$ and Swaminathan \\ Rajaraman $^{1,4,5,7^{*}}$ \\ ${ }^{1}$ NanoScience Technology Center (NSTC), University of Central Florida, Orlando, FL 32816, \\ ${ }^{2}$ AxoSim, Inc., New Orleans, LA 70112, \\ ${ }^{3}$ Department of Chemistry, University of Central Florida, Orlando, FL 32816, \\ ${ }^{4}$ Burnett School of Biomedical Sciences, University of Central Florida, Orlando, FL, 32827, \\ USA, \\ ${ }^{5}$ Department of Electrical \& Computer Engineering, University of Central Florida, Orlando, FL \\ 32826, USA, \\ ${ }^{6}$ Department of Biomedical Engineering, Tulane University, New Orleans, LA 70118 \\ ${ }^{7}$ Department of Materials Science \& Engineering, University of Central Florida, Orlando, FL, \\ 32826, USA. \\ *Swaminathan.Rajaraman@ucf.edu
}

Number of pages: Five (5)

Figures: S1-S3

Table: S1 


\section{SUPPLEMENTARY INFORMATION}

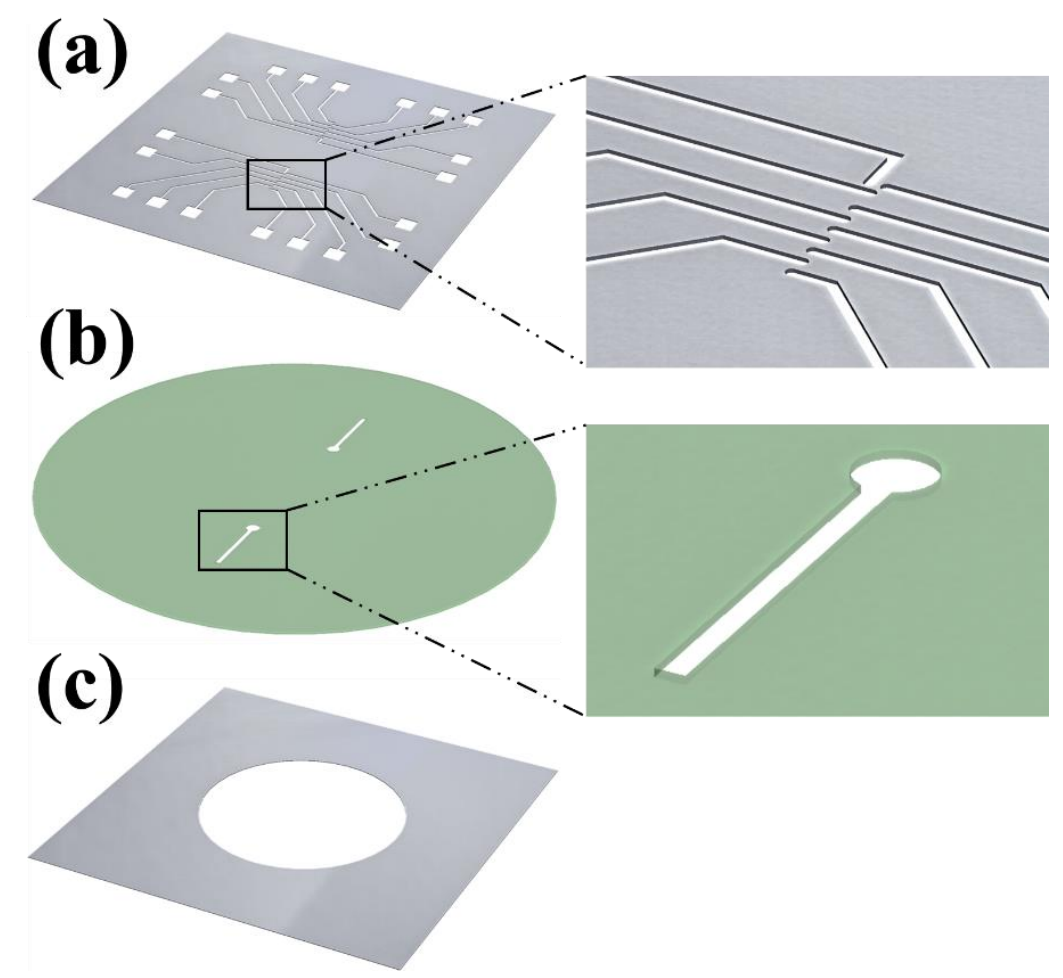

Figure S1: (a) Schematic of the shadow mask used for metallization; (b) Micromilled biocompatible laminate "gross" insulation layer; (c) Shadow mask for the deposition of $\mathrm{SiO}_{2}$. 

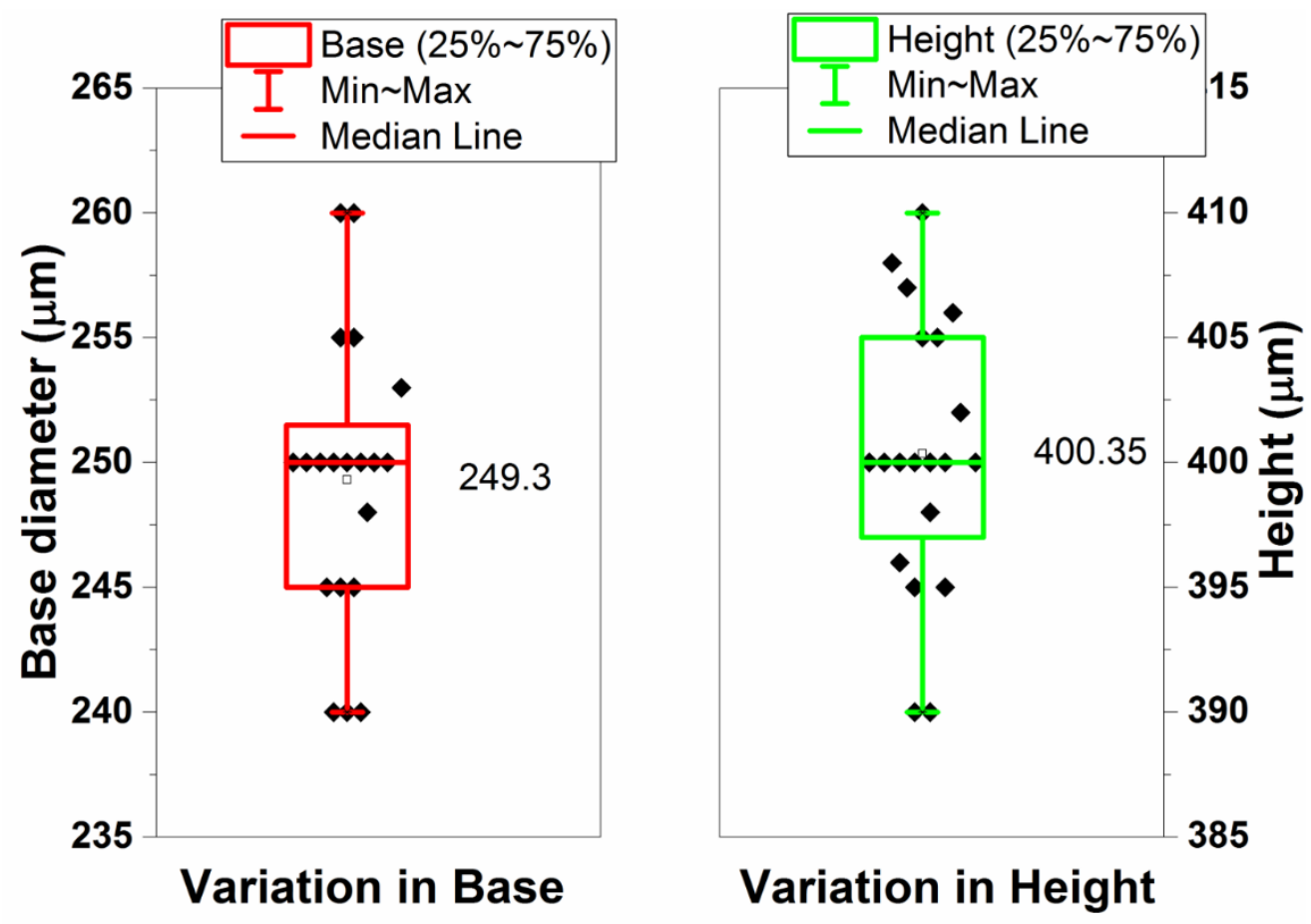

Figure S2: Box plot of the base diameter and height of the 3D printed microtowers ( $N=3$ devices) showing the interquartile range, median, minimum and maximum values and the mean of $249.3 \mu \mathrm{m}$ and $400.35 \mu \mathrm{m}$ for the base diameter and height respectively. The design values of the base diameter and height are $250 \mu \mathrm{m}$ and $400 \mu \mathrm{m}$ respectively. 


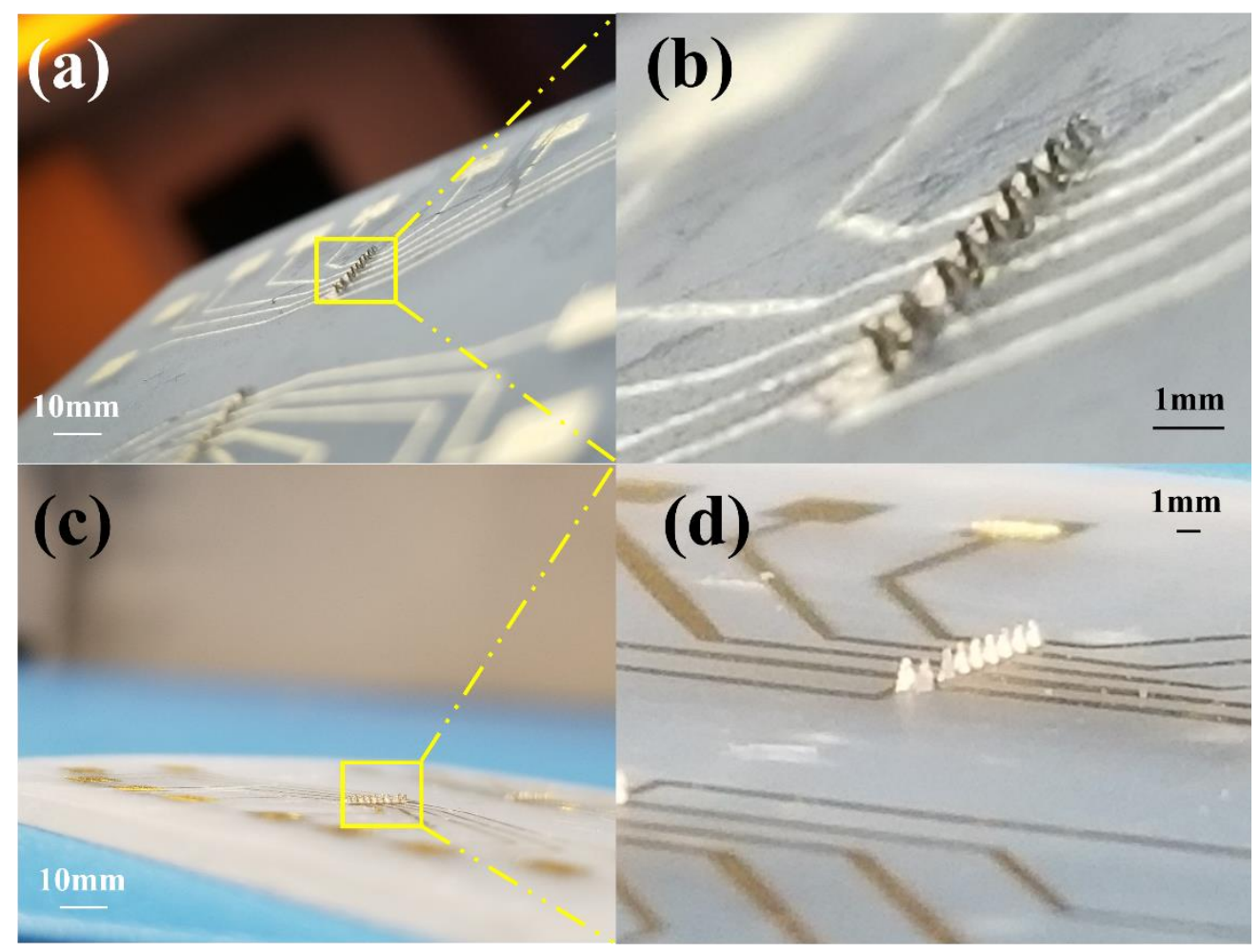

Figure S3: (a) Photomicrographs of ten recording/stimulating sites after electroless plating of platinum with (b) close up of the electrodes depicting the deposition of a black layer of micro-porous platinum; (c) Photomicrographs of the ten recording/stimulating sites before electroless plating of platinum with (d) close up of the electrodes showing shiny golden appearance. 
Table S1: 3D printing technologies used for realizing 3D electrode arrays with advantages and disadvantages of each technology

\begin{tabular}{|c|c|c|c|}
\hline $\begin{array}{l}\text { Sl. } \\
\text { No. }\end{array}$ & $3 \mathrm{D}$ printing technique & Advantages & Disadvantages \\
\hline 1 & $\begin{array}{l}\text { 3D nanoparticle printing } \\
\text { (Aerosol jet printing })^{1,2}\end{array}$ & $\begin{array}{l}\text { - } \text { No support structures needed } \\
\text { for 3D printing. } \\
\text { - 3D printing possible on } \\
\text { flexible materials. } \\
\text { - Low resolution down to } 10 \mu \mathrm{m} \text {. } \\
\text { - Multi-material 3D printing } \\
\text { possible. }\end{array}$ & $\begin{array}{l}\text { - High costs and need of expensive } \\
\text { equipment } \\
\text { - } \text { Difficulty in mass production. } \\
\text { Challenging in terms of adding } \\
\text { different functionalities. } \\
\text { - Fabrication a custom board is } \\
\text { needed to route signals from high } \\
\text { density microelectrode array to } \\
\text { probing pads. }\end{array}$ \\
\hline 2 & Selective Laser Sintering ${ }^{3}$ & $\begin{array}{l}\text { - Low resolution down to } 30 \mu \mathrm{m} \text {. } \\
\text { - } \quad \text { Need for inert gas chambers to } \\
\text { reduce oxidation }\end{array}$ & $\begin{array}{l}\text { - High costs and need of expensive } \\
\text { equipment. } \\
\text { - Limited material palette. } \\
\text { - Packaging of the device is } \\
\text { difficult }\end{array}$ \\
\hline 3 & Inkjet printing ${ }^{4-8}$ & $\begin{array}{l}\text { - Printing on soft materials like } \\
\text { PDMS-, agarose-, and gelatin- } \\
\text { based substrates. } \\
\text { - } \begin{array}{l}\text { Multi-material 3D printing } \\
\text { possible. }\end{array}\end{array}$ & 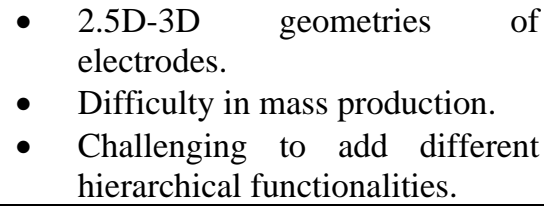 \\
\hline 4 & $\begin{array}{l}\text { Micro-Stereolithography, } \\
\text { Digital Light Processing 3D } \\
\text { Printing (our work) }\end{array}$ & $\begin{array}{l}\text { - Low cost and benchtop } \\
\text { equipment. } \\
\text { - Low resolution down to } 25 \mu \mathrm{m} \text {. } \\
\text { - Wide material palette. } \\
\text { - Simple to add hierarchical } \\
\text { - functionalities. } \\
\text { - Packaging is co-printed with } \\
\text { 3D MEA structure }\end{array}$ & $\begin{array}{l}\text { - Need of support structures to } \\
\text { realize the 3D printed part. } \\
\text { - Multi-material printing is } \\
\text { challenging. }\end{array}$ \\
\hline
\end{tabular}

\section{References:}

1. Saleh, M. S.; Ritchie, S.; Nicholas, M. A.; Bezbaruah, R.; Reddy, J. W.; Chamanzar, M.; Yttri, E. A.; Panat, R., The CMU Array. A 3D Nano-Printed, Fully Customizable Ultra-High-Density Microelectrode Array. bioRxiv 2019, 742346.

2. Yang, H.; Rahman, M. T.; Du, D.; Panat, R.; Lin, Y., 3-D printed adjustable microelectrode arrays for electrochemical sensing and biosensing. Sensors and Actuators B: Chemical 2016, 230, 600-606.

3. $\quad$ Roberts, R. C.; Tien, N. C. In 3D printed stainless steel microelectrode arrays, 2017 19th International Conference on Solid-State Sensors, Actuators and Microsystems (TRANSDUCERS), IEEE: 2017; pp 1233-1236.

4. $\quad$ Adly, N.; Weidlich, S.; Seyock, S.; Brings, F.; Yakushenko, A.; Offenhäusser, A.; Wolfrum, B., Printed microelectrode arrays on soft materials: from PDMS to hydrogels. npj Flexible Electronics 2018, 2 (1), 1-9.

5. $\quad$ Chortos, A.; Hajiesmaili, E.; Morales, J.; Clarke, D. R.; Lewis, J. A., 3D Printing of Interdigitated Dielectric Elastomer Actuators. Advanced Functional Materials 2020, 30 (1), 1907375.

6. Skylar-Scott, M. A.; Mueller, J.; Visser, C. W.; Lewis, J. A., Voxelated soft matter via multimaterial multinozzle 3D printing. Nature 2019, 575 (7782), 330-335.

7. Tetsuka, H.; Shin, S. R., Materials and technical innovations in 3D printing in biomedical applications. Journal of Materials Chemistry B 2020, 8 (15), 2930-2950.

8. $\quad$ Lind, J. U.; Busbee, T. A.; Valentine, A. D.; Pasqualini, F. S.; Yuan, H.; Yadid, M.; Park, S.-J.; Kotikian, A.; Nesmith, A. P.; Campbell, P. H., Instrumented cardiac microphysiological devices via multimaterial three-dimensional printing. Nature materials 2017, 16 (3), 303-308. 